\title{
CONTEXTUALIZAÇÃO NO ENSINO DE QUÍMICA: UMA ANÁLISE DOS DCNEM E PCNS NA CONSTRUÇÃO DE UM ENSINO MÉDIO SIGNIFICATIVO
}

\section{CONTEXT ON CHEMISTRY TEACHING: AN ANALYSIS OF THE PCNS AND DCNEM ON THE CONSTRUCTION OF A SIGNIFICANT HIGH SCHOOL}

Vilma Braga de Oliveira e Maria José Herculano Macedo *

Instituto Federal do Espírito Santo - Campus Vitória (*)

E-mail: pchiste@ifes.edu.br

\begin{abstract}
Resumo
O presente trabalho analisa a proposta dos documentos Diretrizes Curriculares Nacionais para o Ensino Médio (DCNEM) e os Parâmetros Curriculares Nacionais para o Ensino Médio (PCNEM) no que se refere à contextualização do ensino de química. Neste objetivo buscou-se caracterizar objetivamente a proposta destes documentos para tornar efetivamente mais significativo a componente curricular Química para os alunos do Ensino Médio, desmistificando o papel dos professores enquanto mediadores do conhecimento e sua constante necessidade de melhorias dos métodos e técnicas adotados atualmente e acima de tudo na fomentação da busca de inovações e da ressignificação dos conceitos químicos abordados em sala de aula.
\end{abstract}

Palavras-chave: ensino médio. química. contextualização.

\begin{abstract}
This paper analyzes the response of the documents National Curriculum Guidelines for Secondary Education (DCNEM) and National Curricular Parameters for High School (PCNEM) regarding the contextualization of teaching Chemistry. With this goal we sought to characterize objectively the proposal to make these documents more effectively significant chemical curricular component for high school students, demystifying the role of teachers as mediators of knowledge and its constant need of improving methods and techniques currently used and above all in search of innovation and reconsidering the chemical concepts covered in class.
\end{abstract}

Keywords: high school. chemistry. contextualization. 


\section{INTRODUÇÃO}

A construção do conhecimento segundo Piaget se dá através da interação entre o sujeito e o objeto, sendo o principal objeto do conhecimento o meio, abrangendo seus aspectos físicos e culturais (GARCIA, 1998). Vigotsky entendia que a aprendizagem não é uma mera aquisição de informações, não acontecia a partir de uma simples associação de ideias armazenadas na memória, mas era um processo interno, ativo e interpessoal (NEVES e DAMIANI, 2006). Segundo Paulo Freire um verdadeiro processo de ensino-aprendizagem ocorre em conjunto, onde ensinar não é transmitir conhecimento, mas criar possibilidades de autonomia e construção em uma via de mão dupla, em que "quem ensina aprende ao ensinar e quem aprende ensina ao aprender" (SOUZA, 2006). Destes pensadores vê-se que dar a conhecer, fazer conhecer e acima de tudo tornar o conhecimento ferramenta de transformação não é tarefa fácil, e que o aprendizado interrelaciona o ser ao meio que habita. Nota-se que o processo de ensino-aprendizagem encontra-se em constante transformação da mesma forma que o ser humano é caracterizado por seu dinamismo.

As DCNEM e os PCN do Ensino Médio são uma proposta de relacionar as competências correspondentes à área de Ciências da Natureza, Matemática e suas Tecnologias, e a Química está inserida no componente curricular obrigatório Ciências da Natureza, decorrente da LDB que integrou as áreas de conhecimento. Diante disso faz-se necessário uma análise crítica das propostas destes documentos quanto aos aspectos metodológicos de facilitação do processo de ensino-aprendizagem, da disponibilidade de ferramentas que auxiliem o processo de ensinoaprendizagem e o tornem mais eficiente e significativo.

\section{PERCURSO METODOLÓGICO}

Este trabalho consiste numa análise crítica dos documentos DCNEM, PCN e PCN+ quanto as suas propostas e estratégias de contextualização do ensino de química. Para tal foi adotada as metodologia de leitura crítica e interpretativa relacionados à implementação das propostas dos DCNEM e PCNs objetivando a crescente melhoria da qualidade do Ensino Médio através dos processos de contextualização e resignificação do ensino de química. 


\section{RESULTADOS E DISCUSSÃO}

O documento Diretrizes Curriculares Nacionais para o Ensino Médio (DCNEM) não contempla um conceito sobre o termo contextualização, porém este é citado algumas vezes para descrever a sua forma de apresentação, planejamento e os objetivos propostos por este documento no que concerne a sua absorção. Na primeira vez que este termo é citado ele auxilia na descrição da forma de apresentação do Ensino Médio, enfatizando que, em todas as suas formas de oferta e organização, ele deve se basear na integração de conhecimentos gerais e, quando for o caso, técnico-profissionais realizados na perspectiva da interdisciplinaridade e da contextualização.

Na segunda vez que o referido termo aparece, ele retrata a organização curricular, dizendo que o currículo deve contemplar as quatro áreas do conhecimento, com tratamento metodológico que evidencie a contextualização e a interdisciplinaridade ou outras formas de interação e articulação entre diferentes campos de saberes específicos. Descreve ainda que a organização por áreas de conhecimento não dilui nem exclui componentes curriculares com especificidades e saberes próprios construídos e sistematizados, mas implica no fortalecimento das relações entre eles e a sua contextualização para apreensão e intervenção na realidade, requerendo planejamento e execução conjugados e cooperativos dos seus professores.

E na última vez que este termo aparece torna-se evidente a forma de oferta e organização do Ensino Médio, relatando que a interdisciplinaridade e a contextualização devem assegurar a transversalidade do conhecimento de diferentes componentes curriculares, propiciando a interlocução entre os saberes e os diferentes campos do conhecimento (BRASIL, 2012).

Estes documentos buscam de forma não muito objetiva, mas com características fundamentalmente sociológicas, explicitar as habilidades básicas e as competências específicas que se espera desenvolver com os alunos em Biologia, Física, Química e Matemática nesse nível escolar, em decorrência do aprendizado dessas disciplinas e das tecnologias a elas relacionadas. As Diretrizes Curriculares Nacionais para o Ensino Médio não apresentam uma fórmula para a contextualização, porém descreve sua forma de apresentação e planejamento. Primeiro, enfatizando que, em todas as suas formas de oferta e organização, ela deve se basear na integração de conhecimentos gerais e, quando for o caso, técnico-profissionais, realizados na 
perspectiva da interdisciplinaridade; diz que o currículo deve contemplar as quatro áreas do conhecimento, com tratamento metodológico que evidencie a contextualização e a interdisciplinaridade ou outras formas de interação e articulação entre diferentes campos de saberes específicos, descreve ainda que a organização por áreas de conhecimento não dilui nem exclui componentes curriculares com especificidades e saberes próprios construídos e sistematizados, mas implica no fortalecimento das relações entre eles e a sua contextualização para apreensão e intervenção na realidade, requerendo planejamento e execução conjugados e cooperativos dos seus professores; e, por fim, torna-se evidente que a interdisciplinaridade e a contextualização devem assegurar a transversalidade do conhecimento de diferentes componentes curriculares, propiciando a interlocução entre os saberes e os diferentes campos do conhecimento (BRASIL, 2012).

Nesse intuito as DCNEM orientam ainda que, na perspectiva de reduzir a distância entre as atividades escolares e as práticas sociais, o Ensino Médio deve ter uma base unitária sobre a qual podem se assentar possibilidades diversas: no trabalho, como preparação geral ou, facultativamente, para profissões técnicas; na ciência e na tecnologia, como iniciação científica e tecnológica; nas artes e na cultura, como ampliação da formação cultural. Assim, o currículo do Ensino Médio deve organizar-se de modo a assegurar a integração entre os seus sujeitos, o trabalho, a ciência, a tecnologia e a cultura, tendo o trabalho como princípio educativo, processualmente conduzido desde a Educação Infantil.

Segundo as Diretrizes Curriculares Nacionais para Educação Básica, "a prontidão para o exercício da autonomia intelectual são uma conquista paulatina e requerem a atenção de todas as etapas do processo de formação do indivíduo" e, dos princípios e finalidades que orientam o Ensino Médio como preparação para conclusão do processo formativo da Educação Básica, destaca-se que o indivíduo ao final desta etapa formativa deve ser capaz de compreender os fundamentos científicos e tecnológicos presentes na sociedade contemporânea relacionando a teoria com a prática, caracterizando dessa forma uma formação contextualizada.

Nota-se daí que o processo de ensino-aprendizagem encontra-se em constante transformação haja vista que o ser humano está em efetivo processo de construção do seu ser, e este movimento é dinâmico e complexo, especialmente em dias como hoje em que a velocidade e a qualidade das 
informações na maioria das vezes não constroem, mas destroem. Destroem principalmente a possibilidade de uma análise critica da informação que lhes é transmitida, ou melhor, que lhes é ofertada como mercadoria de liquidação.

Neste sentido a recomendação de contextualização nos PCNEM é uma proposta para que o Ensino Médio efetivamente propicie um aprendizado útil à vida e ao trabalho, no qual as informações, o conhecimento, as competências, as habilidades e os valores desenvolvidos sejam instrumentos reais de percepção, satisfação, interpretação, julgamento, atuação, desenvolvimento pessoal ou de aprendizado permanente, evitando tópicos cujos sentidos só possam ser compreendidos em outra etapa de escolaridade (BRASIL, 1999a; BRASIL, 2002).

A sociedade e seus cidadãos interagem com o conhecimento químico por diferentes meios. A promoção do conhecimento químico em escala mundial, nestes últimos quarenta anos, incorporou novas abordagens, objetivando a formação de futuros cientistas, de cidadãos mais conscientes e também o desenvolvimento de conhecimentos aplicáveis ao sistema produtivo, industrial e agrícola. Apesar disso, no Brasil, a abordagem da Química escolar continua praticamente a mesma.

O ser humano, na luta pela sua sobrevivência, sempre teve a necessidade de conhecer, entender e utilizar o mundo que o cerca. Na interpretação do mundo através das ferramentas da Química é essencial que se explicite seu caráter dinâmico. Assim, o conhecimento químico não deve ser entendido como um conjunto de conhecimentos isolados, prontos e acabados, mas sim uma construção da mente humana, em contínua mudança. Para tanto, o PCN orienta que o componente curricular Química deve ter como objetivos da contextualização sócio-cultural levar o aluno a reconhecer aspectos químicos relevantes na interação individual e coletiva do ser humano com o ambiente, reconhecer o papel da Química no sistema produtivo, industrial e rural, reconhecer as relações entre o desenvolvimento científico e tecnológico da Química e aspectos sócio-político-culturais; e reconhecer os limites éticos e morais que podem estar envolvidos no desenvolvimento da Química e da tecnologia (BRASIL, 1999a; BRASIL, 2002).

Ricardo e Zylbersztajn (2007) declaram que qualquer consenso em relação a uma compreensão acerca da contextualização também está longe de existir e que a maioria a entende como estando relacionada ao cotidiano do aluno, ou que a contextualização só é possível com uma infraestrutura 
adequada para realização de experimentos, ou ainda que a contextualização em química refere-se a levar o aluno a imaginar os fenômenos químicos retratados. Os PCN+ relacionam a interdisciplinaridade e as competências como inseridas no processo de contextualizar ao afirmar que essas duas se desenvolvem e surgem do contexto. Santos e Mortimer em 1999 já retratavam a problemática do reducionismo do significado da contextualização para o ensino de química que em muitas vezes é aplicado às simples exemplificações do conhecimento químico nos fatos cotidianos.

Para Santos et al, 2012, contextualizar é construir significados, incorporando valores que explicitem o cotidiano, com uma abordagem social e cultural, que facilitem o processo da descoberta. É levar o aluno a entender a importância do conhecimento e aplicá-lo na compreensão dos fatos que o cercam, e, para contextualizar um conteúdo, o professor deve relacionar o mesmo com questões sociais, políticas e econômicas, uma vez que esteja em consonância com os conhecimentos dos alunos diante das situações encontradas no cotidiano, e assim trabalhar o conteúdo em foco. Já para Santos, 1999, a contextualização possui diferentes funções, dentre as quais a de motivar o aluno, facilitar a aprendizagem e formá-lo para o exercício da cidadania e para isso é fundamental que sejam discutidos em sala de aula aspectos tecnológicos, econômicos, ambientais, políticos, éticos e sociais relacionados à temas científicos presentes na sociedade.

\section{CONSIDERAÇÕES FINAIS}

Os documentos analisados não apresentam conceitos fechados ou engessados sobre contextualização, porém oferecem mecanismos para seu entendimento, compreensão e absorção dos recursos necessários a sua melhor aplicação.

Diante do exposto, entende-se que o conhecimento científico não pode ser apreendido de forma isolada e que os subsídios da contextualização e da interdisciplinaridade devam ser intimamente explorados pelos docentes a fim de que o processo de ensino aprendizagem seja ressignificado e que desperte nos discentes a real necessidade do domínio dos conceitos químicos e sua importância para sua vida individual e na sociedade. E por fim que a ciência seja uma ferramenta para o desenvolvimento do senso crítico deste individuo afim de que o mesmo possa tornar-se membro cada vez mais efetivo da comunidade que ele integra. 


\section{REFERÊNCIAS}

BRASIL, Ministério da Educação, Secretaria da Educação Média e Tecnológica. Parâmetros Curriculares Nacionais: Ensino Médio. Brasília: Ministério da Educação, 1999a.

BRASIL, Secretaria de Educação Média e Tecnológica. PCN+ Ensino Médio: orientações educacionais complementares aos Parâmetros Curriculares Nacionais. Ciências da Natureza, Matemática e suas Tecnologias. Brasília: MEC, SEMTEC, 2002.

BRASIL. Ministério da Educação e do Desporto. Conselho Nacional de Educação. Câmara da Educação Básica. Resolução n.2, de 30 de janeiro de 2012. Define Diretrizes Curriculares Nacionais para o Ensino Médio. Diário Oficial da União. Brasília, DF, 5 ago. 2012b.

GARCIA, S.M.S. 1998. A construção do conhecimento Segundo Jean Piaget. Ensino em Revista, 6 (1): 17-28.

NEVES, R. A.; DAMIANI, M.F. 2006. Vygotsky e as teorias da aprendizagem. UNIrevista, 1 (2): 1-10.

RICARDO, E.C.; ZYLBERSZTAJN, A. 2007. Os parâmetros curriculares nacionais na formação inicial dos professores das ciências da natureza e matemática do Ensino Médio. Investigações em Ensino de Ciências, 12 (3): p.339-355.

SANTOS, E.P.; SILVA, B.C.F.; SILVA, G.B. A contextualização como ferramenta didática no ensino de química. VI Colóquio internacional, educação e contemporaneidade. 20 a 22 de setembro de 2012. Sergipe

SANTOS, W.L.; MORTIMER, E.F. A dimensão social do ensino de Química: um estudo exploratório da visão dos professores. II ENPEC. Anais do II ENPEC. Valinhos, CDRom, 9 p., set, 1999.

SOUZA, M.R. 2006. Por uma educação antropológica: comparando as ideias de Bronislaw Malinowski e Paulo Freire. Revista Brasileira de Educação, 11 (33): 487-564. 